\title{
Cochlospermum regium: conservação e atividade química e biológica
}

\author{
Antonio Carlos Pereira de Menezes Filho ${ }^{\mathrm{a}^{*}}$ \\ ${ }^{a}$ Instituto Federal de Educação, Ciência e Tecnologia Goiano, Brasil \\ *Autor correspondente (astronomoamadorgoias@gmail.com)
}

\section{N F O}

\section{Keywords}

Cochlospermaceae

Bixaceae

savanna Cerrado

domain

endangered flora

plant endemism
Palavras-chaves Cochlospermaceae Bixaceae domínio Cerrado flora em risco de extinção endemismo vegetal

\begin{abstract}
A B S T R A C T
Cochlospermum regium: conservation and chemical and biological activity

Cochlospermum regium is an important plant species for both floristic and herbal medicine. The species has seed development and protocols for breaking dormancy and high germination rates are necessary, since it is a plant explored daily in the field, where the population and root gatherers seek the terrestrial organ (rhizome or xylopodium) for the preparation of bottles and powder for consumption, used to relieve and treat numerous infectious forms. Thus, the work aimed to raise bibliographic data from studies among them, articles, books, master's dissertations on the conservation of the species observing data on the dormancy break and germination, and on the chemical and biological activities exerted by the numerous ways in which the species. Plant organs of $C$. regium are used. Through the reviews it was possible to verify numerous germination protocols and several works that aimed to identify the classes of compounds and their biological activities. In this review it is possible to observe that $C$. regium is extensively studied allowing new drugs and food preservation through antioxidant and microbial actions to enable the use of this plant species. In addition, the protocols presented in this study have high germination rates and may help future reforestation projects and inclusion of $C$. regium in other environments or even in other biomes perpetuating the species.
\end{abstract}

\section{R E S U M O}

O Cochlospermum regium é uma importante espécie vegetal tanto para o meio florístico, quanto para a fitoterapia. A espécie apresenta desenvolvimento por sementes sendo necessário protocolos para quebra de dormência e altas taxas de porcentagem de germinação, visto que, é uma planta explorada diariamente no campo, onde a população e raizeiros buscam o órgão terrestre (rizoma ou xilopódio) para o preparo de garrafadas e pós para consumo, utilizado para aliviar e tratar numerosas formas infecciosas. Desta forma, o trabalho visou levantar dados bibliográficos de estudos dentre eles, artigos, livros, dissertações de mestrados sobre a conservação da espécie observando dados sobre a quebra de dormência e germinação, e sobre as atividades química e biológica exercida pelas inúmeras formas em que os órgãos vegetais de $C$. regium são utilizadas. Através das revisões foi possível verificar inúmeros protocolos de germinação e vários trabalhos onde visaram identificar as classes de compostos e suas atividades biológicas. Nesta revisão é possível observar que o $C$. regium é exaustivamente estudado possibilitando que novos fármacos e meios de conservação de alimentos através das ações antioxidantes e microbianas possibilitem o uso desta espécie vegetal. Além disso, os protocolos apresentados neste estudo, apresentam altas taxas de germinação, podendo auxiliar futuros projetos de reflorestamento e inclusão de $C$. regium em outros ambientes ou mesmo em outros biomas perpetuando a espécie. 


\section{INTRODUÇÃO}

O Cerrado devido a suas inúmeras fitofisionomias passou de bioma para domínio nos últimos anos. Considerado o segundo maior em área territorial, bem como nas composições florística e faunística, quando comparado entre os outros biomas do Brasil e do mundo. Atualmente este domínio apresenta cerca de 2 milhões de $\mathrm{km}^{2}$, entorno de $22 \%$ de todo o território nacional, estando atrás apenas do bioma Amazônico (Bueno et al., 2018; Bambi et al., 2016). Este domínio é também chamado de transição pois a vida animal possui transito passando de um bioma ao outro, havendo constante movimentação da fauna.

Além disso, o Cerrado apresenta banco florístico único, com espécies endêmicas e de características compartilhadas entre os outros ambientes naturais, não somente no território brasileiro, mas também com áreas de florestas de Cerrado na Bolívia e Paraguai (Ribeiro; Walter, 2008). Sabe-se através dos últimos levantamentos da flora, um total de 11.000 espécies de vegetais são nativas deste ambiente, sendo que, deste, entorno de 4.400 espécies são endêmicas deste domínio (Bueno et al., 2018; Myers et al., 2000).

Atualmente o Cerrado vem sofrendo perdas constantes na área de preservação ripária, caça ilegal de animais e plantas, que favoreçe a biopirataria e uso indiscriminado de espécies com efeitos fitoterápicos. Além disso, este domínio sofre constantes queimadas crimonosas feitas por fazendeiros e invasores de áreas que almeijam o aumento das unidades de produção agrícola, desmatando completamente suas áreas de proteção permanente, que previstas por lei $\mathrm{n}^{\mathrm{o}}$. 12.651/2012 (Art. $3^{\circ}$ e $4^{\circ}$ ) do Código Florestal (BRASIL, 2012) e Art. 225 da constituição, para efeito ambiental e agrícola onde devem compor suas unidades rurais, podendo usufruir com atividades agrossilvipastoris, de ecoturismo e de turismo rural (Bambi et al., 2016; Tundisi; Tundisi, 2008). A ganância por mais dinheiro é o grande vilão deste importante ambiente natural, que não somente apresenta flora e fauna únicas no mundo, mas também está intimamente envolvido na movimentação climática dentro do Brasil (Noleto et al., 2020; Silva et al., 2007).

Importantes gêneros vegetais como o Cochlospermum (Kunth), que integraram a Família Cochlospermaceae Engler (classe: Dicotiledoneae De Candolle), hoje incluídas na Família Bixaceae (In: Bixaceae, 2016), possuindo cerca de 11 espécies distribuídas pelas regiões tropicais das Américas e África (Duarte et al., 2014; Sólon et al., 2009). No Brasil são identificadas as espécies $C$. regium, $C$. onirocense e C. vitifolium, nativas do domínio Cerrado
(Menezes Filho e Castro, 2019; Sólon et al., 2012). Uma das espécies endêmicas desse ambiente é o [Cochlospermum regium (Mart. ex Schrank) Pilger], conhecido popularmente por algodão-do-campo ou algodãozinho-do-cerrado. É uma espécie terrícola, arbustiva, que apresenta ocorrência frequente em áreas de Cerrado da região Centro-Oeste do Brasil (Camillo et al., 2009).

O C. regium apresenta grande e profundo rizoma axial carnoso, numerosas folhas por seguimento do tipo simples e palmatilobadas, apresentando aroma característico quando esmagadas; são plantas lenhosas, com floração anual apresentando flores vistosas de fácil identificação, de coloração amarela, levemente aromáticas do tipo terminal, paniculada e hermafroditas, florescendo entre os meses de maio-agosto; os frutos são do tipo secos, capsulares deiscentes, loculicida, oblongos, também com aroma característico, e numeroras sementes reniformes, de testa lisa, crustácea, de coloração castanho-escuras, densamente tomentosas, pilosas, sedosas por fruto (Menezes Filho; Castro, 2019; Arunachalam et al., 2019; Joly, 2002; Kirisawa, 1981).

Atualmente o $C$. regium encontra-se na lista de plantas com princípios ativos utilizados na fitomedicina com importantes atividades biológicas e farmacêuticas como antiinflamatório (Lima et al., 1995), antiuceroso (Lewis; Hanson, 1991), nos tratamentos de dermatites (Ritto; Kato, 1998), abcessos (Salles et al., 1997), artrite reumatóide (Ritto, 1996), dentre outras, estando incluida na lista de espécies vegetais ameaçadas de extinção, devido o extrativismo ilegal e a destruição dos habitats naturais. Este estudo visa levantar os dados de pesquisas relacionadas a sua conservação e sobre suas atividades químicas e biológicas que o $C$. regium apresenta, através do levantamento de informações em artigos, livros e dissertações.

\section{MATERIAL E MÉTODOS}

O método de elaboração da pesquisa empregado, foi com base em artigos, dissertações e livros que apresentam como destaque a espécie Cochlospermum regium da Família Bixaceae, espécie nativa do domínio Cerrado. As especificações foram por meio de seleções utilizando palavras-chave Cochlospermum regium, algodão-do-cerrado, Cochlospermum, Bixaceae, Algodãozinho-do-cerrado.

Na Tabela 1, estão apresentadas as Revistas/Journals/Revistas onde a pesquisa gerou 
resustados para a revisão de literatura sobre

Cochlospermum regium.

Tabela 1 - Resultados das pesquisas sobre as palavras-chave na revisão de literatura científica para Cochlospermum regium.

\begin{tabular}{|c|c|}
\hline Revista/Journal/Revista* & $\begin{array}{c}\text { Editora/Publishing/Compañía } \\
\text { de publicidad** }\end{array}$ \\
\hline Acta Scientiarum & OJS/PKP \\
\hline Advances in Phytomedicine & Elsevier \\
\hline Revista Arquivos Científicos & OJS/PKP \\
\hline Biomedicine e Pharmacotherapy & Elsevier \\
\hline BMC Proceedings & Springer \\
\hline Brazilian Journal of Biology & SciELO \\
\hline Ciência Rural & SciELO \\
\hline Contraception & Elsevier \\
\hline Ecosystems & Springer \\
\hline Evidence-Based Complementary and Alternative Medicine & Hindawi \\
\hline European Journal of Medicinal Plants & Publons \\
\hline Fitoterapia & Elsevier \\
\hline FLOVET - Boletim do Grupo de Pesquisa da Flora, Vegetação e Etnobotânica & OJS/PKP \\
\hline Forest Ecology and Management & Elsevier \\
\hline Genetics and Molecular Biology & SciELO \\
\hline Globo Science and Technology & OJS/PKP \\
\hline Heringeriana & OJS/PKP \\
\hline Iheringia & SciELO \\
\hline International Journal of Antimicrobial Agents & Elsevier \\
\hline Industrial Crops and Products & Elsevier \\
\hline Journal of Pharmacy and Pharmacology & Wiley Oline Library \\
\hline Journal of Functional Foods & Elsevier \\
\hline Journal of Medicinal Plants Research & AJ \\
\hline Journal of Ethnopharmacology & Elsevier \\
\hline Lecta & BVS \\
\hline Lead Molecules from Natural Products & Elsevier \\
\hline Mutation Research/Genetic Toxicology & Elsevier \\
\hline Mutation Research/Fundamental and Molecular Mechanisms of Mutagenesis & Elsevier \\
\hline Nature & Nature \\
\hline Natural Product Communication & SAGE Journals \\
\hline Natural Product Research & Taylor e Francis Online \\
\hline Plant and Soi & Springer \\
\hline Progress in Medicinal Chemistry & Elsevier \\
\hline Plant Physiology & Elsevier \\
\hline Phytoterapy Research & Wiley Online Library \\
\hline Química Nova & SciELO \\
\hline Revista Eletrônica da Faculdade de Ceres & OJS/PKP \\
\hline Revista Brasileira de Farmacognosia & Springer \\
\hline Revista Brasileira de Botânica & SciELO \\
\hline Revista Brasileira de Plantas Medicinais & SciELO \\
\hline Revista Eletrônica de Farmácia & OJS/PKP \\
\hline Revista de Biologia Neotropical & OJS/PKP \\
\hline Revista Brasileira de Biosciências & OJS/PKP \\
\hline Semina: Ciências Agrárias & OJS/PKP \\
\hline South African Journal of Botany & Elsevier \\
\hline The Plant Cell & ASBP \\
\hline Trends in Parasitology & Elsevier \\
\hline Visão Acadêmica & OJS/PKP \\
\hline
\end{tabular}




\section{RESULTADOS E DISCUSSÃO}

\section{Meios de conservação}

Primeiramente é preciso iniciar o estudo da conservação de $C$. regium discutindo sobre a sua importância, onde pode ser observado inúmeros trabalhos onde vários pesquisadores avaliam suas atividades químicas (classes fitoquímicas) e biológicas (tratamento de doenças, agentes antioxidantes, dentre outras) como possíveis novos isumos farmacêuticos, bem como também utilizado na medicina popular (Menezes Filho et al., 2020; Carvalho et al., 2018; Batista et al., 2014). Visto que, a maioria da população de baixa renda econômica, bem como, sem acesso a drogas comerciais, procuram as plantas para resolver seus males (De Oliveira et al., 2018). Com isso, o extrativismo descontrolado e inconsciente está colocando em risco as áreas onde há pequenas populações de indivíduos de $C$. regium em ambiente natural. Tornando-se necessário que hajam projetos de conservação e de reprodução através da superação de dormência das sementes, para que haja uma potencialização no processo de germinação possibilitando o desenvolvimento de protocolos de germinação para a sobrevivência desta espécie (Albuquerque et al, 2006; Sales, 2001). Embora, Coelho et al. (2008) tenham verificado que o processo de produção de mudas é simples para $C$. regium, é necessário estudos para que as taxas de germinação sejam superiores a $50 \%$, para que haja garantias de um número maior de plântulas.

Dessa forma, nos estudos de Inácio et al. (2015), onde avaliaram sementes de diferentes tamanhos pequenas, médias e grandes de $C$. regium armazenadas por um período de 13 meses, onde observaram baixa taxa de germinação entre 31,$67 ; 21,67$ e $36,67 \%$, respectivamente. Os pesquisadores avaliam também que, o tamanho da semente não influencia diretamente e indiretamente nas taxas de germinação, e que as plântulas in vivo devem ser mantidas em substrato enriquecido com areia e as sementes devem ser estimuladas para germinação logo após a colheita. No estudo, é possível dizer que, as sementes de $C$. regium não apresentam longevidade de germinação quando mantidas em temperatura controlada entorno de $26{ }^{\circ} \mathrm{C}$ por um período relativamente longo. De acordo com Adedi et al.
(2014), Kaeser e Kirkman (2012) e Stella et al. (2006), a baixa longevidade é um fator comum em espécies nativas não domesticadas, e a capacidade de manutenção do embrião na fase germinativa varia entre as famílias de vegetais, bem como, o protocolo de armazenamento e a qualidade das sementes.

Batista et al. (2014), avaliaram a quebra de dormência das sementes de $C$. regium com dimetilsulfóxido (DMSO), onde obtiveram taxa de germinação de $80,0 \%$, para escarificação mecânica com $83,75 \%$, para escarificação ácida (ácido sulfúrico dil.) com 75,0\% e em solução de hipoclorito de sódio com $3,75 \%$. Os pesquisadores avaliaram dois tratamentos, um com água e outro com dimetilsulfóxido a $65{ }^{\circ} \mathrm{C}$, onde obtiveram porcentagem de germinação de 4,08 e 87,5\%, respectivamente.

Staller et al. (2004), complementam que, existem os fatores subjacentes que estão ligados a longevidade no processo germinativo de sementes, como a presença e seus teores de vitamina $\mathrm{E}$, e dos hormônios giberélicos (GA1 e GA4). A vitamina E está ligada na limitação da oxidação lipídica não enzimática durante o processo de armazenamento, e também na taxa de germinação e desenvolvimento de plântulas precoces; já as giberelinas vem sendo estudadas como prováveis promissoras no reforço tegumentar das sementes (Bueso et al., 2014).

Nos estudos de Coelho et al. (2008), os pesquisadores avaliaram diferentes condições de luz, temperatura e soluções contendo ácido sulfúrico na germinação de sementes de $C$. regium. Os pesquisadores encontraram o período de 15 dias onde os tratamentos apresentaram o máximo de germinação, exceto para o tratamento claro que apresentou maior taxa de germinação no $16^{\circ}$ dia. Os pesquisadores ainda observaram que 24 horas não foram suficientes para completa absorção de água pelas sementes de $C$. regium no tratamento claro (presença de luz) que é fator de grande importância em maior porcentagem de germinação. Entretanto, Hartmann et al. (1997), discutem sobre o papel da luz na influência de germinação em ambiente controlado e na natureza, sendo distintos, bem como, apresentando taxas de germinação distitnas, em especial em ambiente controlado. No entanto, ainda carece de mais estudos, pois não está bem esclarecido, onde estas variáveis podem apresentar diferentes resultados 
na germinação e no desenvolvimento de plântulas.

No trabalho de Viu et al. (2007), os pesquisadores avaliaram as sementes de $C$. regium para quebra de dormência, onde observaram que as sementes em estudo absorveram cerca de 2,38 vezes o seu peso seco em água destilada, como tratamento pré-germinativo. Um dos quatro tratamentos testados, o $\left(\mathrm{T}_{4}\right)$ apresentou melhores resultados, tanto na quebra de dormência quanto no desenvolvimento em altura de plântulas de $C$. regium em substrato a base de vermiculita, uma espécie de mineral argiloso micáceo. Entretanto, este tratamento, não foi significativo para números de folhas, sendo que dois tratamendos diferentes do anterior nos grupos $\left(T_{2}\right.$ e $\left.T_{3}\right)$, mesmo que não apresentassem diferença estatistica significante apresentou maior promoção em número médio de folhas por indivíduo. Já Sales et al. (2002), apresentam como possível protocolo de quebra de dormência, o uso de solução diluída de ácido sulfúrico, como já é bem conhecido por outros pesquisadores. De acordo com Coelho et al. (2008), a espécie C. regium apresenta sementes fotoblásticas neutras e é classificada na sucessão ecológica como pioneira. Inácio et al. (2010), demonstraram que plantas de $C$. regium se adaptam muito bem em ambos os solos pobre e rico em nutrientes, sendo um dos fatores de distribuição e dispersão em várias fitofisionomias de Cerrado, entretanto, é necessário avaliar também o conteúdo de água destes solos.

Inácio et al. (2011), avaliaram a conservação e micropropagação de $C$. regium em diferentes reguladores de plantas (BAP, Kineti e Zeatin), em diferentes concentrações de sacarose, com adição de ácido indolbutírico (IBA), e meio de cultivo MS complementado com sucrose, sorbitol, pantotenato de cálcio e manitol. Os pesquisadores observaram que mesmo em meio pobre de MS suplementado com apenas $2 \%$ de sucrose, $4 \%$ de manitol e pantotenato de cálcio as sementes germinavam sem necessidade de complementos nutricionais extras. Dentro destas condições cerca de $47,62 \%$ dos explantes sobreviveram, sugerindo que as sementes de $C$. regium não necessitam de complexos procedimentos de reprodução.

$\mathrm{Na}$ natureza a conservação in natura se dá também pela polinização exclusivamente por abelhas dos gêneros Xylocopa, Bombus, Centris e Apis conforme descrito no estudo de Noronha e Gottsberger (1980). O uso de insetos polinizadores proporciona troca de material genético entre os indivíduos de uma ou várias populações de $C$. regium, dentre outras espécies. O uso de filtros coloridos vem apresentando importantes resultados quanto a germinação, como desenvolvido por Sales (2001), onde estudou a germinação das sementes de $C$. regium escarificadas em solução de ácido sulfúrico por 120 min. seguido de embebição em água destilada por $24 \mathrm{~h}$. As sementes foram mantidas sob luz vermelha onde apresentou em estudo, maior taxa de germinação quando comparado ao controle.

Segundo Neto (2016), a manuteção da diversidade genética, deve ser levada em consideração, devido a variabilidade das espécies que assumem importância fundamental para a conservação da biodiversidade. $\mathrm{O}$ autor complementa que, uma espécie não sobrevive sozinha, onde a interdependência entre as condições ambientais e as relações ecológicas estão intimamente ligadas na manutenção das condições para a perpetuação da espécie e maior diversidade biológica e de sua conservação in ou ex situ ocorra.

Os estudos fisiológicos da dormência e da germinação em $C$. regium apresentam importantes dados na literatura, podendo ser utilizados na viabilização de um número maior de sementes germinadas, utilizadas em projetos de reflorestamento de áreas degradadas, em áreas naturais de preservação permanente e ou mesmo na domesticação do vegetal, já que apresentam também importantes dados farmacobotânicos.

\section{Química e classes de compostos farmacologicamente ativos}

Nos estudos mais atuais de Menezes Filho e Castro (2019), e Menezes Filho et al. (2020), os pesquisadores avaliaram os extratos etanólicos do rizoma, galho e folhas, e hidroetanólico floral de C. regium onde observaram a presença das seguintes classes de compostos fitoquímicos por testes qualitativos glicosídeos cardíacos; alcaloides; ácidos orgânicos, exceto no extrato etanólico dos galhos; açúcares redutores e cumarinas estando presentes apenas no extrato etanólico da raiz; saponinas hemolíticas, fenóis, taninos da classe dos catéquicos, flavonoides e catequinas, exceto no extrato etanólico do galho; depsídeos e depsidonas, derivados de benzoquinonas e antraquinonas apenas no extrato etanólico das folhas; esteróides e triterpenóides, exceto no extrato etanólico das folhas; e sesquiterpenolactonas, exceto no extrato etanólico da raiz; e para o extrato floral glicosídeos cardíacos e cianogênicos, ácidos orgânicos, 
saponinas hemolíticas, fenóis, taninos, flavonoides, catequinas, flavononóis, flavanonas, flavanonóis e xantonas. Importantes classes farmacologimanete ativas são observadas em todos os principais órgãos de C. regium, tornando este, um importante vegetal altamente valorizado para a pesquisa e produção de biofármacos.

Arunachalam et al. (2019), identificaram a presença de rutina com média de $16,31 \mu \mathrm{g} \mathrm{mg}^{-1}$, miricetina $13,44 \mu \mathrm{g} \mathrm{mg}^{-1}$ e morin com $0,62 \mu \mathrm{g} \mathrm{mg}^{-}$ ${ }^{1}$ no extrato etanólico do xilopódio (raiz) de $C$. regium. Nos estudos de Pedroso et al. (2019), os pesquisadores obtiveram importantes resultados de compostos químicos no extrato hidrometanólico das raizes de $C$. regium. Teores expressivos de compostos fenólicos totais iguais a 1443,04 mg $\mathrm{EAG} \mathrm{g}^{-1}$, e de flavonoides de 708,75 mg QE g ${ }^{-1}$, ácidos fenólicos determinados em ácido gálico de $114,26 \mathrm{mg} \mathrm{g}^{-1}$, ácido caféico de $40,1 \mathrm{mg} \mathrm{g}^{-1}$ e de ácido elágico igual a $27,9 \mathrm{mg} \mathrm{g}^{-1}$ determinados por cromatografia líquida de alta eficiência, além de compostos químicos com efetiva ação antioxidante determinada em $\beta$-caroteno/ácido linoleico com inibição da oxidação $\operatorname{com} \mathrm{CI}_{50}$ de $85,50 \mu \mathrm{g} \mathrm{mL}^{-1}$, e para os radicais livres DPPH, $\mathrm{ABTS}^{+}$e (malondialdeído) MDA com $\mathrm{CI}_{50}$ de 14,68; 138,71 e $68,88 \mu \mathrm{g} \mathrm{mL}^{-1}$, respectivamente. Carvalho et al. (2018), avaliaram o extrato etanólico da raiz de $C$. regium por cromatografia líquida de alta eficiência onde observaram a presença de ácido gálico e DHK-glicosídeo em concentrações iguais a $22,61 \%$ e $3,07 \%$, respectivamente. Além destes compostos, os pesquisadores quantificaram os teores de fenólicos totais e de taninos com concentrações iguais a $725,5 \mu \mathrm{g} \mathrm{mg}^{-1}(72,5 \%)$ e $214,9 \mu \mathrm{g} \mathrm{m}^{-1}(21,5 \%)$, respectivamente.

Cunha-Laura et al. (2013), corroboram com os estudos de Vasconcelos Filho et al. (2017), onde analizaram o extrato hidroetanólico do xilopódio de $C$. regium. Os autores encontraram a presença das classes químicas de ácidos orgânicos, esteróides, triterpenos, flavonoides, compostos fenólicos e taninos condensados, e a ausência de alcaloides. Pode-se observar que as classes químicas a partir do metabolismo secundário em C. regium variam, podendo ou não estar presentes nos mais diversos tipos de extratos (Firmo et al., 2014; Viecelli; Cruz-Silva, 2009; Gobbo-Neto; Lopes, 2007).

Compostos fenólicos e flavonoides como os encontrados nos extratos de $C$. regium tem sido relatados como eficiêntes agentes antimicrobianos, agindo diretamente na membrana celular acarretando a ruptura e inibindo a síntese de ácidos nucléicos e do metabolismo energético de inúmeros patógenos (Dzoyem et al., 2013; Cushine e Lamb, 2005).

De acordo com Goulas et al. (2014), várias classes de compostos fitoquímicos como os terpenos e taninos apresentam importantes ações bactericidas e fungicidas (Popova et al., 2009; Ho et al., 2001), sendo estas referências de classes químicas do metabolismo secundário observadas também nas folhas de C. regium.

Estudo desenvolvido por Lima et al. (1995), encontraram o composto dihidrocaempferol-3- $O$ $\beta$-glucopiranosídeo pertencente a família das flavononas avaliando o extrato da fração em acetato de etila, este composto apresenta ação analgésica. Ritto et al. (1996) encontraram através de análises fitoquímicas, o isolado acetofenona-1hidroxitetradecanona-3, um éster de ácido $p$ hidroxicinâmico, alguns flavonoides e naringenina nas raízes de $C$. regium.

Vários compostos foram identificados no estudo dirigido por Sólon et al. (2012), onde os pesquisadores encontraram sete derivados fenólicos, os ácidos elágico e gálico, dihidrocaempferol-3- $O-\beta$-glucopiranosídeo, dihidrocaempferol-3- $O-\beta$-(6' '-galoil)-

glucopiranosídeo, pinoresinol e excelsina, e dois triacilbenzenos, a Coclospermina A e B.

Os óleos essenciais outra classe encontrada em C. regium, apresentam importantes estudos, como os desenvolvidos por Inácio et al. (2014), onde os pesquisadores obtiveram 32 compostos no óleo essencial das folhas de $C$. regium sendo o $\beta$ copaen-4- $\alpha$-ol, viridiflorol, biciclogermacreno e longiborneol os compostos majoritários com porcentagens com áreas iguais a 18,$73 ; 12,67$; 8,26 e $7,13 \%$, respectivamente, sendo composto por $96,87 \%$ de sesquiterpenos. Honda et al. (1997), também encontraram óleo essencial na raiz de $C$. regium sendo o único composto majoritário o $\beta$-selineno com teor de $34,1 \%$ em relação ao pico no cromatograma de íons totais por CG-EM. Outras espécies do gênero Cochlospermum como em $C$. angolense também apresentaram conteúdo de sesquiterpenos igual a $68,8 \%$, sendo os compostos majoritários germacreno $\mathrm{D}, \alpha$-cadinol e 10-Epi-cubenol com áreas de 9,4; 7,4 e 6,2\%, respectivamente (Leonardi et al., 2012). Almeida et al. (2005) avaliaram o óleo essencial das folhas de $C$. vitifolium espécie endêmica do domínio Cerrado, onde encontraram os seguintes compostos majoritários $\beta$-cariofileno, $\alpha$-humuleno e $\beta$-pineno 
com área relativa de 46,5; 26,0 e 10,6\%, respectivamente. Vasconcelos Filho et al. (2014) e Inácio (2010), discutem sobre o uso do óleo essencial de $C$. regium como de alto potencial para uso na perfumaria, aromaterapia e aplicações na indústria farmacêutica.

Inácio et al. (2014) avaliaram os extratos das folhas jovens e adultas de $C$. regium quanto a presença de lipídeos, fenóis totais, alcaloides, compostos nitrogenados e taninos, onde todos foram positivos para ambas as amostras de extratos foliares. Sólon et al. (2009), reportam o uso do extrato das raizes de $C$. regium como fonte de taninos, mucilagem, terpenos e compostos fenólicos totais. De acordo com Appezzato-daGloria e Carmello-Guerreiro (2006), os idioblastos são responsáveis pela secreção de inúmeros compostos lipofílicos, mucilagens, proteínas, aminoácidos e óleo essencial em C. regium.

São inúmeros os compostos químicos observados principalmente nos estudos reportados para as raizes (xilopódio) e no órgão foliar, entretanto, ainda é desconhecido os compostos químicos nas flores, frutos e sementes de $C$. regium, carecendo ainda de pesquisa para que se possam conhecer as classes químicas dos metabólitos primários e secundários desta espécie.

\section{Atividades biológicas}

As várias classes químicas do metabolismo secundário apresentam importantes funções farmacológicas sendo empregadas em inúmeros processos biológicos no tratamento de doenças, na prevenção de vários tipos de cânceres, no sequestro de radicais livres envolvidos em problemas genéticos, bem como no desenvolvimento de ações que inibem a inflamação, dor, dentre outras ações, até mesmo no advento de medicamentos que inibem a atividade neural em convulsões e na produção de anestesias.

Nos estudos de Arunachalam et al. (2019), os pesquisadores avaliaram a ação de gastroproteção do extrato etanólico do xilopódio de C. regium, onde observaram excepcional ação contra a bactéria Helicobacter pylori. Os pesquisadores ainda avaliaram em ratos tratados com concentrações do extrato hidroetanólico, onde apresentaram redução glicêmica em jejum. Os autores acrescentam que, outros estudos complementares deverão ser realizados para se conhecer melhor o papel do extrato das raizes de C. regium na hiperglicemia e dos mecanismos envolvidos no potencial antidiabético. Outra importante atividade observada, é a ação de inibição da acetilcolinesterase, os resultados obtidos pelos pesquisadores foram promissores, onde diferentes dosagens inibiram a atividade de acetilcolina esterase em diferetnes estruturas cerebrais.

Quanto a ação hemolítica em células eritrocitárias do tecido hematopoiético em humano, foi obserdado atividade hemolítica no extrato etanólico da raiz de $C$. regium nos estudos desenvolvidos por Menezes Filho e Castro (2019), e nos estudos de Menezes Filho et al. (2020), onde avaliaram o extrato hidroetanólico floral com importante atividade hemolítica, apresentando taxas de hemólise entre 77,16 a $59,20 \%$, e ação fotoprotetora UVA e UVB. Os pesquisadores do primeiro estudo, ainda observaram alta intensidade de hemólise no extrato etanólico dos galhos e média intensidade no extrato etanólico das folhas. Esses foram os primeiros resultados a respeito da atividade hemolítica para estes três órgãos em células do tecido hematopoiético humano, carecendo de estudos para destinar o uso correto, bem como as doses abaixo da $\mathrm{DL}_{50}$ em produtos fitoterápicos com os órgãos aéreos avaliados.

Carvalho et al. (2018), obtiveram alta eficiência como agentes antibacteriano e antifúngico aplicando diferentes concentrações de extrato etanólico das raizes de $C$. regium, contra Pseudomonas aeruginosa e Acinetobacter baumanni gram-negativas não fermentadoras, e discreta para Staphylococcus epidermidis, Staphylococcus aureus e Streptococcus agalactiae gram-positivas. Já para Klebsiella pneumoniae e Escherichia coli gram-negativas e para Listeria monocytogenes gram-positiva não foram satisfatórios. Os pesquisadores observaram também bons resultados fungicidas contra Candida krusei, Candida glabrata, Candida tropicalis e Candida albicans.

Leme et al. (2017), avaliaram in vitro a atividade contra microrganismos uropatogênicos a partir do extrato etanólico das folhas de $C$. regium. Uma baixa atividade de inibição foi observado para E. coli e discreta para C. tropicais, demonstrando que o extrato foliar pode ser utilizado individual ou em conjunto com outros princípios ativos para o uso como antibiótico e antifúngico. Estes dados estão em concordância com os resultados obtidos por Inácio et al. (2016), onde avaliaram várias partes das raízes de $C$. regium, na inibição de crescimento de $C$. albicans ATCC 10231, onde obtiveram boa eficiência de 
inibição. Com isso, pode-se sugerir a substituição do orgão terrestre pelo aéreo, visto que, o órgão terrestre não se regenera, ajudando assim na preservação da espécie. Pereira et al. (2015) e Poppendieck (1981), discutem sobre inúmeros trabalhos com a Família Cochlospermaceae no tratamento de malária, icterícia e lesões hepáticas incluindo C. regium, Cochlospermum trinctorium, Cochlospermum planchonii e Cochlospermum angolensis.

E Silva et al. (2014) encontraram boa eficiência bactericida e fungicida contra C. krusei, Enterococcus faecalis, E. coli e $S$. aureus, já para C. glabrata não houve inibição em diferentes concentrações. Os resultados de E Silva et al. (2014), são promissores, visto que, o fármaco fluconazol já apresenta baixa ação fungistática contra C. krusei, bem como, potencial inibidor no desenvolvimento das bactérias $E$. faecalis e de $E$. coli. Estudos potenciais apresentam o extrato das folhas de C. regium como promissores novos fármacos alternativos no tratamento de infecções causadas por estes microrganismos.

Cunha-Laura et al. (2013), observaram importante ação citotóxica contra células VERO, e evidenciaram potencial e eficiênte atividade antiproliferativa de células HeLa utilizando diferentes dosagens do extrato hidroetanólico do xilopódio de $C$. regium. Os pesquisadores ainda verificaram que não houve potencial mutagênico na ausência ou presença da ativação metabólica (S9) e para estirpes de Salmonella typhimurium, bem como não observaram sinais clínicos de toxicidade em ratas prenhes durante o período organogênico como locomoção, piloereção e diarréia. Os pesquisadores ainda demonstraram que o uso do extrato hidroetanólico de C. regium não apresenta toxicidade materna, bem como não apresentou relação direta teratogênica e sem má formações em fetos. Entretanto, houve aumento no número de fetos mortos e redução da taxa de natalidade, que é uma indicação que o extrato de C. regium apresenta intensa atividade abortiva (Yakubu e Bukoye, 2009).

Atividade bactericida também foi descrita para C. regium, como observado no estudo proposto por Solon et al. (2012), onde os pesquisadores avaliaram a eficiência do extrato hidroetanólico do xilopódio e suas frações na inibição de $S$. aureus, E. coli e $P$. aeruginosa. Andrade et al. (2008), avaliaram a ausência de antimutagenicidade em micronúcleos em camundongos a partir do extrato de $C$. regium. Os pesquisadores relataram que não houve significância na indução do efeito antimutagênico nas condições experimentais, vistos na redução da frequência de eritrócitos policromáticos micronucleados. No estudo desenvolvido por Ceschini e Campos (2006), os pesquisadores observaram a toxicidade do extrato aquoso da raiz de $C$. regium em células imortais não tumorogênicas de mamíferos roedores (hamster chineses) in vitro, entretanto, os pequisadores observaram atividade citotóxica na indução de apoptose em células CHO-K1. Pessoa et al. (2006), apresentaram em um estudo de levantamento de plantas medicinais com potencial atividade anticâncer no Nordeste do Brasil, onde citaram o extrato de $C$. regium com efetiva ação biológica no tratamento de tumor de Walker, com inibição de $2 \%$.

Já no estudo de Nunes e Carvalho (2003), avaliando a atividade mutagênica promovida por C. regium em células germinativas masculinas de Drosophila melanogaster, em diferentes concentrações do extrato aquoso da raiz, mostraram que as concentrações não induziram mutagenicidade avaliada pela perda do anel $\mathrm{X}$ em D. melanogaster. Os estudos de toxicidade e mutagenicidade são de grande importância pois possibilitam a compreensão dos efeitos ativos de um composto ou do sinergismos de vários compostos (Portis et al., 2016).

Nunes et al. (2003), em estudo de levantamento etnobotânico de espécies utilizadas e comercializadas na cidade de Campo Grande, Mato Grosso do Sul, onde os entrevistados de diferentes bases sociais e econômicas disseram utilizar as raizes de $C$. regium para cura e controle do colesterol, na depuração do sangue, para inflamação uterina e ovariana, como antiinflamatório geral e da pele, para infecções da próstata, feridas internas e externas e como laxante.

Toledo et al. (2000), verificaram a ação tóxica aguda e subaguda do extrato hidroetanólico das raízes in natura de $C$. regium em ratos. Onde observaram nas primeiras 3 horas de administração de frações do extrato reação de piloereção e dificuldades de locomoção, e nas doses mais altas os animais apresentaram inquietação e ptose, que persistiu por $24 \mathrm{~h}$. Com 5 dias foram relatados, diarréia e diminuição da atividade motora, modificações visuais de cor nos rins e fígado também foram relatadas em uma análise rápida de necropsia. Os animais que vieram a óbito apresentaram na investigação mais detalhada de necrópsia peritonite, ascite, hemorragia intestinal e alterações macroscópicas 
no tecido hepático, como alterações de cor e petéquias. Entretanto, o extrato hidroetanólico de C. regium apresentou baixa ação tóxica aguda $\mathrm{e}$ subaguda.

Já Imanishi et al. (1999) e Edenharder et al. (1997), avaliaram as classes de taninos e flavonoides de $C$. regium onde observaram promissores resultados como agente antimutagênico. Castro et al. (1994), investigaram o extrato da raiz de $C$. regium onde encontraram ação antiedematogênica.

Importantes atividades biológicas são demonstradas em estudos avaliando principalmente os extratos da raiz, galhos e folhas. Entretanto ainda pouco se sabe sobre os óleos essenciais que muitas das vezes, apresentam importantes dados de atividade antioxidante, antifúngica, antibacteriana, larvicida, inseticida, dentre outras, podendo ser empregados em processos químicos, farmacológicos, fitoremediadores, como agentes agrícolas e no processamento de alimentos.

\section{CONCLUSÕES}

O estudo bibliográfico aqui apresentado, traz um conjunto de dados sobre os aspectos de conservação, química e atividades farmacológicas e biológicas de Cochlospermum regium. Discutindo os vários protocolos de propagação avaliando diferentes métodos de quebra de dormência e taxas de germinação, bem como as classes de compostos fitoquímicos, ações farmacológicas testadas em diversos modelos celulares e em ações biológicas promovidas pelos mais variados órgãos do vegetal. Em especial no rizoma (xilopódio) e nas folhas, onde se concentram o maior número de estudos fitoquímicos e biológicos para C. regium. Este trabalho de revisão, possibilitou minucioso levantamento sobre as pesquisas com $C$. regium, devido a esparsos dados científicos. O autor não determinou uma linha do tempo, pois existem numerosos dados de trabalhos antigos e atuais havendo uma ocilação considerável na linha do tempo em número de publicações, entretanto, ainda pouco se conhece sobre esta espécie. O trabalho mais rescente sobre $C$. regium, realizado por Menezes Filho et al. (2020), avalia com ineditismo, o extrato floral, abrindo novas possibilidades de estudo.

Pode-se ainda concluir que, o material biológico de $C$. regium nas inúmeras pesquisas, são exclusivamente do domínio Cerrado, visto que, esta espécie é exclusivamente deste ambiente, podendo ainda dizer que, não há variabilidade genética entre populações distantes, carecendo ainda de pesquisas sobre domesticação do vegetal e utilizar a espécie em projetos de reflorestamento, garantindo que haja troca de material genético entre grupos de indivíduos em diferentes regiões, garantindo assim a conservação da espécie, bem como avaliar outras classes fitoquímicas e ações biológicas para o desenvolvimento de biofármacos, insumos bioagrícolas e de biotecnologia, desta importante e marcante espécie no domínio Cerrado.

\section{REFERÊNCIAS BIBLIOGRÁFICAS}

Abedi M, Bartelheimer M, Poschlod P. Effects os substrate type, moisture and its interations on soil seed survival of three Rumex species. Plant and Soil, v.374, n.1-2, p.485495, 2014. https://doi.org/10.1007/s11104-013-1903-x

Albuquerque MCF, Coelho MFB, Albrecth JMF. Germinação de sementes de espécies medicinais do Cerrado. In: I Seminário Matogrossense de etnobiologia e etnoecologia e II Seminário Centro-Oeste de plantas medicinais. 2002.

Almeida SCX, Lemos TLG, Silveira ER, Pessoa ODL. 2005. Volatile and non-volatile chemical constituents of Cochlospermum vitifolium (Willdenow) Ssprengel. Química Nova, v.28, p.57-60, 2005. http://dx.doi.org/10.1590/S0100-40422005000100012

Andrade LS, Santos DB, Castro DB, Guillo LA, Chen-Chen L. Absence of antimutagenicity of Cochlospermum regium (Mart. and Schr.) Pilger 1924 by micronucleus test in mice. Brazilian Journal of Biology, v.68, n.1, p.155-159, 2008. http://dx.doi.or/10.1590/S1519-69842008000100022

Apezzato-da-Glória B, Carmello-Guerreiro SM. Plant Anatomy. $2^{\text {a }}$ Ed., UFV: Viçosa, p.438, 2006.

Arunachalam K, Damazo AS, Pavan E, Oliveira DM, Figueiredo FF, Machado MT, Blogun SO, Soares IM, Barbosa RS, Alvim TC, Ascêncio SD, Martins DTO. Cochlospermum regium (Mart. ex Schrank) Pilg.: Evaluation of chemical profile, gastroprotective activity mechanism of action of hidroethanolic extract of its Xylopodium in acute and chronic experimental models. Journal Ethnopharmacology, v.233, p.101-114, 2019 https://doi.or/10.1016/j.jep.2019.01.002

Bambi P, Rezende RS, Cruz TMS, Batista JEA, Miranda FGG, Dos Santos LV, Júnior JFG. Diversidade da flora fanerogâmica de três matas de galeria no bioma Cerrado. Heringeriana, v.10, n.2, p.147-167, 2016.

Batista PF, Costa AC, Megguer CA, Lima JS, Sales JF. Overcoming dormancy and characterization of germination in Cerrado 'algodãozinho' seeds treated with dimethyl sulphoxide. South African Journal of Botany, v.92, p.8993, 2014. https://doi.org/10.1016/j.sajb.2014.02.004

Bueno ML, Oliveira-Filho AT, Pontara V, Pott V, Pott A, Damasceno-Júnior GA. Flora arbórea do Cerrado de Mato Grosso do Sul. Iheringia, v.73 (supl.), p.53-64, 2018. https://doi.org/10.21826/2446-8231201873s53 
Bueso E, Munoz-Bertomeu J, Campos F, Brunaud V, Martinez L, Sayas E, Ballester P, Yenush L, Serrano R. Arabidopsis thaliana HOMEOBOX25 uncovers a role for gibberellins in seed longevity. Plant Physiology, v.164, n.2, p.999-1010, 2014. https://doi.org/10.1104/pp.113.232223

Brasil. Presidência da República, Casa Civil, Subchefia para Assunto Jurídicos, Lei n ${ }^{\circ} .12 .651$, de 25 de maio de 2012. Brasília, 25 de maio de 2012; $191^{\circ}$ da Independência e $124^{\circ}$ da República.

http://www.planalto.gov.br/ccivil_03/_ato2011-

2014/2012/lei/112651.htm. Acesso em 22 de julho de 2020

Camillo J, Scherwinski-Pereira JE, Vieira RF, Peixoto JR. Conservação in vitro de Cochlospermum regium (Schrank) Pilg.-Cochlospermaceae sob regime de crescimento mínimo. Revista Brasileira de Plantas Medicinais, v.11, n.2, p.184-189, 2009. https://doi.org/10.1590/S151605722009000200012

Carvalho RS, Carollo CA, Magalhães JC, Palumbo JMC, Boaretto AG, Nunes e Sá IC, Ferraz AC, Lima WG, De Siqueira JM, Ferreira JMS. Antibacterial and antifungal activities of phenolic compound-enriched ethyl acetate fraction from Cochlospermum regium (Mart. et Schr.) Pilger roots: Mechanisms of action and synergism with tannin and gallic acid. South African Journal of Botany, v.114, p.181-187, 2018.

https://doi.org/10.1016/j.sajb.2017.11.010

Castro MAS, Siqueira JM, Krieger-Amorin LW, Souza KCB. Efeito analgésico e antiedematogênico do Cochlospermum regium (Mart.) Pilger ('algodãozinho'). In: Medicinal Plants Symposium of Brazil, v.13, Universidade Federal do Ceará, Fortaleza, Ceará, 1994.

Ceschini L, Campos ÉG. Cytotoxic effects of Cochlospermum regium (Mart e Schrank) Pilger aqueous root extrct on mammalian cells. Journal of Ethnopharmacology, v.103, p.302-305, 2006. https://doi.org/10,1016/j.jep.2005.07.026

Coelho MdeFB, Sales DM, Albuquerque MCF. Germinação e emergência de Cochlospermum regium (Schrank) Pilg. em diferentes substratos. Revista Brasileira de Plantas Medicinais, v.10, n.4, p.90-96, 2008.

Coelho MdeFB, Sales DM, Dombroski JLD, De Azevedo $\mathrm{RAB}$, Albuquerque MCdeFe. Condições de luz e temperatura na germinação de sementes de algodão do campo [Cochlospermum regium (Schrank) Pilger - Bixaceae]. Revista de Biologia Neotropical, v.5, n.2, p.23-31, 2008. https://doi.org/10.5216/rbn.v5i2.9814

Cunha-Laura AL, Oliveira RJ, De Barros ALC, De Siqueira JM, Vieira MdoC, Auharek SA. Maternal exposure to Cochlospermum regium: a toxicological evaluation. Revista Brasileira de Farmacognosia, v.23, n.2, p.374-378, 2013. https://doi.org/10.1590/S0102-695X2013005000005

Cushine TP, Lamb AJ. Antimicrobial activity of flavonoids. International Journal of Antimicrobial Agents, v.26, n.5, p.343-356, 2005. https://doi.org/10.1016/j.ijantimicag.2005.09.002

De Oliveira VB, Mezzomo TR, De Moraes EF. Conhecimento e uso de plantas medicinais por usuários de unidade básicas de saúde na região de Colombo, PR. Revista Brasileira de Ciências da Saúde, v.22, n.1, p.57-64, 2018. https://doi.org/10.22478/ufpb.2317$6032.2018 \mathrm{v} 22 \mathrm{n} 1.30038$
Duarte MR, Oliveira RB, Dranka ERK, Yano M. Anatomia foliar de algodãozinho-do-cerrado: Cochlospermum regium (Schrank) Pilg., Bixaceae. Visão Acadêmica, v.15, n.2, p.5-16, 2014.

http://dx.doi.org/10.5380/acd.v15i2.38312

Dzoyem JP, Hamamoto H, Ngameni B, Ngadjui BT, Sekimizu K. Antimicrobial action mechanism of flavonoids from Dorstenia species. Drug Discoveries e Therapeutics, v.7, n.2, p.66-72, 2013.

https://doi.org/10.5582/ddt.2013.v7.2.66

Edenharder R, Rauscher R, Platt KL. The inhibition by flavonoids of 2-amino-3-methylimidazo [4,5-f] quinoline metabolic activation to a mutagen: a structure-activity relationship study. Mutation Research/Fundamental and Molecular Mechanisms of Mutagenesis, v.379, n.1, p.21-32, 1997. https://doi.org/10.1016/S0027-5107(97)00085-7

E Silva JLSC, Bicudo BP, Rodrigues AB, Mendonça MMM, Borges, RR, De Almeida AA, De Oliveira KMP. Evaluation of antibacterial and antifungal activity of ethanolic extract of Cochlospermum regium (Cochlospermaceae) leaf, a medicinal plant from the Cerrado of Brazil. In: 5th Congress of the Brazilian Biotechnology Society, BioMed Central, BMC Proceedings, v.8, (Suppl 4), p.72, 2014.

Firmo WCA, Miranda MV, Coutinho GSL, Silveira LMS, Olea RSG. Estudo fitoquímico e avaliação da atividade antibacteriana de Lafoensia pacari (Lythraceae). Publicatio UEPG, Ciências Biológicas e da Saúde, v.20, n.1, p.7-12, 2014.

https://doi.org/10.5212/publicatio\%20uepg.v20i1.6541

Gobbo-Neto L, Lopes NP. Plantas medicinais: fatores de influência no conteúdo de metabólitos secundários. Química Nova, v.30, n.2, p.374-381, 2007. http://dx.doi.org/10.1590/S0100-40422007000200026

Goulas V, Exarchou V, Kanetis L, Gerothanassis IP. Evaluation of the phytochemical content, antioxidant activity and antimicrobial properties of mountain tea (Sideritis syryaca) decotion. Journal of Functional Foods, v.6, n.1, p.248-258, 2014. https://10.1016/j.jff.2013.10.014

Hartmann HT, Kester DE, Davies Jr FT, Geneve RL. Plant propagation: principles and pratices. 6th Ed., Prentice Hall, New Jersey, 770 p., 1997.

Honda NK, Brum RL, Hess SC, Cru AB, Moretto E. Antibacterial activity of Cochlospermum regium essential oil. Fitoterapia, v.68, n.1, p.79-80, 1997.

Ho KY, Tsai CC, Huang JS, Chen CP, Lin TC, Lin CC. Antimicrobial activity of tannin components of Vaccinium vitis-idaea L. Journal of Pharmacy and Pharmacology, v.53, n.2, p.187-191, 2001. https://doi.org/10.1211/0022357011775389

Imanishi H, Sasaki YF, Ohta T, Watanabe M, Kate T, Shirasu Y. Tea tannin components modify the induction of sister-chromatid exchanges and chromosome aberrations in mutagen-treated cultured mammalian cells and mice. $\mathrm{Mu}-$ tation Research/Genetic Toxicology, v.259, n.1, p.79-87, 1991. https://doi.org/10.1016/-165-1218(91)90111-x

Inácio MC, Bertoni BW, Franca SC, Pereira MAS. In vitro seeds germination and ex vitro plants development of algodãozinho-do-campo. Ciência Rural, v.40, n.11, p.22942300, 2010. 
Inácio MC, Paz TA, Bertoni BW, Pereira AMS. Germination of Cochlospermum regium seeds: influence os seed size, vials, vial sealing in vitro, and substrate in vivo. European Journal of Medicinal Plants, v.6, n.1, p.26-33, 2015. https://doi.org/10.9734/EJMP/2015/15077

Inácio MC, Paz TA, Bertoni BW, Vieira MAR, Marques MOM, Pereira MAS. Histochemical investigation of Cohlospermum regium (Schrank) Pilg. leaves and chemical composition of its essential oil. Natural Product Research, v.28, n.10, p.727-731, 2014. http://dx.doi.or/10.1080/14786419.2013.879133

Inácio MC, Bertoni BW, França SC, Pereira MAS. In vitro conservation and low cost micropropagation of Cochlospermum regium (Mart. ex. Scharank). Journal of Medicinal Plants Research, v.5, n.20, p.4999-5007, 2011.

Inácio MC. Agronomic, chemical and biological study Cochlospermum regium (Mart. ex Scharank): A medicinal plant of the cerrado. Dissertação de mestrado. Universidade Estadual Paulista, p.118, 2010.

Inácio MC, Paz TA, Bertoni BW, Pereira MAS. Effect of environmental and phenological factors on the antimicrobial activity of Cochlospermum regium (Schrank) Pilg. roots. Acta Scientiarum, v.38, n.4, p.467-473, 2016 http://dx.doi.org/10.4025/actasciagron.v38i4.30567

Joly AB. Botânica: introdução à taxonomia vegetal. $13^{\mathrm{a}}$ Ed., São Paulo: Ed. Nacional, 2002.

Kaeser MJ, Kiskman LK. Seed longevity of 12 native herbaceous species in a fire-maintained pine savanna after 8 years of burial. Forest Ecology and Management, v.281, n.1, p.68-74, 2012.

https://doi.org/10.1016/j.foreco.2012.06.019

Kirizawa M. Contribuição ao conhecimento morfo-ecológico e do desenvolvimento anatômico dos órgãos vegetativos e de reprodução de Cochlospermum regium (Mart. e Sch.) Pilger - Cochlospermaceae. Tese doutorado. Universidade de São Paulo, 436 p., 1981.

Leonardi M, Giovanelli S, Cioni PL, Flamini G, Pistelli L. Evaluation of volatile constituents of Cochlospermum angolense. Natural Product Communictions, v.7, p.629-632, 2012. https://doi.org/10.1177/1934578X1200700522

Leme DEM, Rodrigues AB, Almeida-Apolonio AA, Dantas FGS, Negri MFN, Svidzinski TIE, Mota JS, Cardoso CAL, De Oliveira KMP. In vitro control of uropathogenic microorganisms with the rthanolic extract from the leaves of Cochlospermum regium (Schrank) Pilger. Evidence-Based Complementary and Alternative Medicine, p.1-8, 2017. https://doi.org/10.1155/2017/4687154

Lewis AC, Hanson PJ. 4 Anti-ulcer drugs of plant origin. Progress in Medicinal Chemistry, v.28, p.201-231, 1991. https://doi.org/10.1016/S0079-6468(08)70365-5

Lima DP, Castro MAS, Mello JCP, Siqueira JM, Kassab NM. A flavanone glycoside from Cochlospermum regium. Fitoterapia, v.66, p.545-546, 1995.

Menezes Filho ACP, Castro CFS. Avaliação dos extratos vegetais de Cochlospermum regium em um Cerrado ralo. Global Science and Technology, v.13, n.01, p.01-17, 2019.

Menezes Filho, ACP, Santos MC, Castro CFS. Estudo fitoquímico, bioativo, fotoprotetor e físico-químico do extrato floral do extrato floral de algodãozinho do Cerrado [Co- chlospermum regium Schrank. (Pilg.)] - Bixaceae. Revista Arquivos Científicos, v.3, n.4, 2020.

Myers N, Mittermeier RA, Mittermeier CG, Fonseca GAB, Kent J. Biodiversity hotspots for conservations priorities. Nature, v.403, n.6772, p.853-858, 2000. https://doi.org/10.1038/35002501

Neto GG. Cochlospermaceae regium (Mart. e Schrank) Pilger - Bixaceae. FLOVET - Boletim do Grupo de Pesquisa da Flora, Vegetação e Etnobotânica, v.1, n.8, p.27-34, 2016.

Noronha MRP, Gottsberger GA. A polinização de Aspilia floribunda (Asteraceae) e Cochlospermum regium (Cochlospermaceae) e a relação das abelhas visitantes com outras plantas do cerrado de Botucatu, Estado de São Paulo. Revista Brasileira de Botânica, v.3, n.1/2, p.67-77, 1980.

Noleto PF, Noleto PC, de Sousa KF, Guimarães APM. Influência das queimadas para a qualidade orgânica de duas áreas do Cerrado tocantinense. Natural Resources, v.10, n.1, p.1-9, 2020. http://doi.org/10.6008/CBPC22379290.2020 .001 .0001

Nunes WB, Carvalho S. Evaluation of the mutagenic potential of Cochlospermum regium in Drosophila melanogaster male germ cells. Genetics and Molecular Biology, v.26, n.4, p.545-549, 2003. http://dx.doi.org/10.1590/S141547572003000400020

Nunes GP, Silva MF, Resende UM, Siqueira JM. Plantas medicinais comercializadas por raizeiros no centro de Campo Grande, Mato Grosso do Sul. Revista Brasileira de Farmacognosia, v.13, n.2, p.83-92, 2003.

https://doi.org/10.1590/S0102-695X2003000200004

Pedroso TFM, Bonamigo TR, Da Silva J, Vasconcelos P, Félix JM, Cardoso CAL, Souza RIC, Dos Santos AC, Volobuff CRF, Formagio ASN, Trichez VDK. Chemical constituents of Cochlospermum regium (Schrank) Pilg. root and its antioxidant, antidiabetic, antiglycation, and anticholinesterase effects in Wistar rats. Biomedicine e Pharmacotherapy, v.111, p.1383-1392, 2019. https://doi.org/10.1016/j.biopha.2019.01.005

Pessoa C, Costa-Lotufo LV, Leyva A, De Moraes MEA, De Moraes MO. Anticancer potential of northeast brazilian plants. Advances in Phytomedicine, v.2, p.197-211, 2006. https://doi.org/10.1016/S1572-557X(05)02012-X

Pereira C, Barros L, Alves MJ, Pereira L, Santos-Buelga C, Ferreira ICFR. Phenolic profile and antimicrobial activity of different dietary supplements based on Cochlospermum angolensis Welw. Industrial Crops and Products, v.74, p.412-416, 2015. https://doi.org/10.1016/j.indcrop.2015.05.056

Poppendieck H-H. Cochlospermaceae. New York Botanical Gardens, Bronx NY, 1981.

Portis IG, Figueiredo FRG, Pena RV, Hanusch AL, De Sousa LP, Machado RC, De Silva CC, Da Cruz AD. Bioensaio citogenético para a caracterização da mutagenicidade e citotoxicidade da espécie Cochlospermum regium. Revista Eletrônica da Faculdade de Ceres, v.5, n.1, 2016. https://doi.org/10.36607/refacer.v5i1.3357

Ribeiro JF, Walter BMT. As principais fitofisionomias do Bioma Cerrado. In Cerrado: ecologia e flora (Sano SM, 
Almeida SP, Ribeiro JF, eds.). Embrapa Cerrados, Planaltina, $151-212$ p. 2008.

Ritto JLA, Oliveira FD, Carvalho JED, Dias PC. Avaliação farmacológica do extrato fluido de Cochlospermum regium (Mart. et Schr.) Pilger. Lecta-USF, v.14, n.2, p.27-36, 1996.

Ritto JLA. Caracterização farmacológica da droga e do extrato fluído de algodãozinho-do-campo-Cochlospermum regium (Marte t Schr) Pilger. Dissertação de mestrado, universidade de São Paulo, 1996.

Ritto JLA, Kato ETM. Estudo morfo-histológico de raízes de algodãozinho-do-campo Cochlospermum regium (Mart. et. Schr.) Pilger. Lecta, v.16, p.97-109, 1998.

Sales DM, Coelho MFB, Albuquerque MCF, Ferronato A. Superação da dormência por ácido sulfúrico em sementes de algodão do campo Cochlospermum regium (Mart. e Schr.) Pilg. - Cochlospermaceae. Revista Brasileira de Plantas Medicinais, v.4, p.65-71, 2002.

Sales DM. Germinação de sementes de [Cochlospermum regium (Mart. ex Schr.) Pilg.] Cochlospermaceae. Dissertação de mestrado. Universidade Federal do Mato Grosso, 2001.

Salles AH, Reis GMCL, Zurlo MA. Hortomedicina do Cerrado. Jardim Botânico de Brasília, p. 5, 1997.

Sattler SE, Gilliland LU, Magallanes-Lundback M, Pollard M, Della Penna D. Vitamin E is essential for seed longevity and for preventing lipid peroxidation during germination. The Plant Cell, v.16, n.6, p.1419-1432, 2004. https://doi.org/10.1105/tpc.021360

Stella JC, Battles JJ, Orr BK, McBride JR. Synchrony of seed dispersal, hydrology and local climate in a semi-arid river reach in California. Ecosystems, v.9, n.7, p.1200-1214, 2006. https://doi.org/10.1007/s10021-005-0138-y

SILVA CJ, SANCHES L, BLEICH ME, LOBO FA, NOGUEIRA JS. Produção de serrapilheira no Cerrado e Floresta de Transição Amazônia-Cerrado do Centro-Oeste Brasileiro. Acta Amazonica, v.37, n.4, p.543-548, 2007. https://doi.org/10.1590/S0044-59672007000400009

Sólon S, Brandão LFG, De Siqueira JM. O gênero Cochlospermum Kunth com ênfase nos aspectos etnobotânicos, farmacológicos, toxicológicos e químicos de Cochlospermum regium (Mart. ex Schr.) Pilger. Revista Eletrônica de Farmácia, v.6, n.3, p.1-22, 2009. https://doi.org/10.5216/ref.v6i3.7649

Sólon S, Carollo CA, Brandão LFG, De Macedo CS, Klein A, Dias-Júnior CA, Siqueira JM. Phenolic derivatives and other chemical compounds from Cochlospermum regium. Química Nova, v.35, n.6, p.1169-1172, 2012. http://dx.doi.org/10.1590/S0100-40422012000600019

Toledo MI, Siqueira JM, Araújo LCL, Oga S. Acute and subacute toxicitiy of Cochlospermum regium (Mart. e Schr.) Pilger. Phytotherapy Research, v.14, p.359-361, 2000. http://doi.org/10.1002/1099 1573(200008)14:5<359::AID-PTR642>3.0.CO;2-0

Tundisi JG, Tundisi TM. Limnologia. São Paulo: Oficina de Textos, $1^{\text {a }}$ Ed., 632p. 2008.

Vasconcelos Filho SC, Ferreira ALL, Vasconcelos JM, Silva LS, Pereira LCS. Secretory structures in Cochlospermum regium (Schrank) Pilg. (Bixaceae): Distribution and histochemistry. Journal of Medicinal Plant Research, v.8, n.26, p.947-952, 2014. https://10.5897/JMPR2014.5460

Viu AFM, Da Costa EA, Viu MAO, Campos LZdeO, Santos SC. Germinação e desenvolvimento de plântulas de [Cochlospermum regium (Schrank) Pilger] - (algodão-docampo) em diferentes substratos. Revista Brasileira de Biociências, v.5, supl.2, p.957-959, 2007.

Viecelli CA, Cruz-Silva CTA. Efeito da variação no potencial alelopático de Sálvia. Semina: Ciências Agrárias, v.30, n.1, p.39-46, 2009.

Yakubu MT, Bukoye BB. Abortifacient potentials of the aqueous extract of Bamusa vulgaris leaves in pregnant Dutch rabbits. Contraception, v.80, n.3, p.308-313, 2009. https://doi.org/10.1016/j.contraception.2009.03.003 